\title{
Financial Behavior Sebagai Moderasi Pengaruh Financial Knowledge dan Financial Attitude Terhadap Financial Distress pada Generasi Milenial
}

\author{
Cicilia Erna Susilawati*1, Vania Dewi Sugiarto² \\ Program Pasca Sarjana Unika Widya Mandala Surabaya ${ }^{1,2}$ \\ *correspondence e-mail: erna-s@ukwms.ac.id
}

\begin{abstract}
Millennials is very familiar with technology that makes it easier for them to access information and to do many things easily. However, this often makes the millennial generation less careful in managing finances, and causes financial problems. The study wanted to find out how the influence of financial knowledge and financial attitude on financial distress through financial behavior in the millennial generation. Data was collected using a questionnaire for millennial generation respondents who already have their own income. Data analysis using path analysis. The results show that financial knowledge does not directly affect financial distress, but financial knowledge has an effect on financial distress through financial behavior. This indicates that financial knowledge does not guarantee that millennials will avoid financial distress, if this knowledge is not applied in financial behavior. The results also show that financial attitude affects financial distress either directly or through financial behavior.
\end{abstract}

Keywords : Financial distress; financial behavior; financial knowledge,; financial attitude; millenial

\section{Pendahuluan}

Generasi milenial merupakan generasi yang akrab dengan teknologi, mudah beradaptasi dengan lingkungan dan memiliki karakteristik percaya diri. Kecangihan teknologi dan perkembangan dunia digital saat ini memberikan akses bagi generasi millenial untuk dapat melakukan banyak hal dengan mudah. Hampir sebagian besar kebutuhan dan aktivitas dapat dilakukan secara online. Menurut Halidi (2021) generasi milenia memiliki perilaku konsumtif, percaya diri dan berpegang teguh pada pendiriannya sehingga cenderung kesulitan dalam mengelola keuangannya. Kemudahan dalam melakukan berbagai transaksi finansial juga menjadi salah satu faktor yang menyebabkan generasi milenial terlena dan mengalami masalah keuangan (financial distress). (Chinen, 2012) enyatakan bahwa individu yang memiliki kemampuan untuk membuat keputusan keuangan dengan tidak akan mengalami financial distress di masa depan dan menunjukkan perilaku keuangan (financial behavior) yang sehat serta mampu menentukan proritas kebutuhan. Financial behavior yang sehat ditunjukkan oleh aktivitas perencanaan, pengelolaan, serta pengendalian keuangan yang baik. Menurut (Lajuni, Bujang and Yacob, 2018), pengetahuan keuangan (financial knowledge) dan perilaku keuangan (financial behavior) efek yang lebih besar daripada religiusitas. Penelitian lain (Arifin, 2018), pengetahuan keuangan (financial knowledge) dan sikap keuangan (financial attitude) berpengaruh terhadap perilaku keuangan (financial behavior).

Sedangkan perilaku keuangan memediasi hubungan antara pengetahuan keuangan dan sikap keuangan terhadap kepuasan finansial. Sementara itu, menurut (Mien and Thao, 2015), pribadi dengan external locus of control yang tinggi memiliki perilaku keuangan yang lebih buruk. Generasi milenial seharusnya sudah memiliki rencana dan mengidentifikasi hal-hal apa yang akan dilakukan untuk mengelola keuangan. Namun, sebagian generasi milenial dianggap masih memiliki banyak tantangan dalam mengelola keuangan. Menurut (Anna, Consulting and Stone, 2019), di antara semua generasi, generasi millenial cenderung rapuh secara finansial dalam memenuhi kebutuhan yang mendesak. Menurut (Lusardi, 2012), literasi keuangan meupakan keterampilan yang harus dikuasai oleh setiap individu untuk memperbaiki taraf hidupnya dengan upaya pemahaman terhadap perencanaan dan pengalokasian sumber daya keuangan yang tepat dan efisien. Sementara itu, (Huston, 2010) mendefinisikan financial behavior sebagai keahlian yang dimiliki oleh individu dengan kemampuannya untuk mengelola pendapatannya agar tercapai peningkatan kesejahteraan finansial.(Eccles et al., 2014) menyebutkan bahwa perilaku manajemen arus kas yang termasuk sebagai financial behavior yang tidak memadai menyebabkan fianncial distress. Selain itu, perilaku keuangan yang tidak suka menyiapkan dana darurat atau berinvestasi juga dapat menyebabkan seseorang mengalami financial distress atau kesulitan keuangan. Menurut (Hogarth and Hilgert, 2002) seseorang yang memiliki financial knowledge yang baik cenderung memiliki financial behavior yang yang bertanggung jawab. Dengan kata lain, financial knowledge dan financial behavior memiliki hubungan yang positif. Sementara itu, financial attitude menurut (Trial et al., 2008) merupakan keadaan pikiran, pendapat, dan penilaian tentang keuangan. Sedangkan menurut (Rajna and Moshiri, 2011) financial attitude adalah kecenderungan psikologis yang diekspresikan ketika mengevaluasi praktik manajemen keuangan yang direkomendasikan dengan beberapa tingkatan kesepakatan dan ketidaksepakatan. (Adiputra, 2021) menyebutkan bahwa financial attitude adalah penerapan prinsip-prinsip keuangan untuk menciptakan dan mempertahankan nilai melalui pengambilan keputusan dan manajemen sumber daya yang tepat, sehingga financial attitude akan menentukan financial behavior seseorang. 
Berdasarkan fenomena tersebut penelitian ini dilakukan untuk mengetahui tentang pengaruh financial knowledge (pengetahuan keuangan) dan financial attitude (sikap keuangan) terhadap financial distress (kesulitan keuangan) melalui financial behavior (perilaku keuangan) pada generasi milenial. Hasil penelitian ini diharapkan dapat memberikan gambaran tentang pengelolaan keuangan bagi generasi millenial dan bisa dijadikan pertimbangan agar dapat mengurangi kemungkinan terjadinya financial distress di masa yang akan datang.

\section{Metode}

Penelitian ini menggunakan sampel sebanyak 167 reponden yang memenuhi persyaratan sebagai generasi milenial dan telah memiliki penghasilan sendiri. Kriteria generasi milenial adalah mereka yang lahir pada tahun 19802000 atau pada saat penelitian ini dilakukan, responden berusia 20-40 tahun. Data diperoleh dengan menggunakan kuesioner yang dikirimkan melalui Google Form. Kuesioner disusun berdasarkan indikator dari masing-masing variabel, dimana penelitian ini terdapat 4 variabel yaitu Financial Knowledge (FK), Financial Attitude (FA) sebagai independen variabel, Financial Behavior (FB) sebagai variabel moderasi dan Financial Distress (FD sebagai variabel dependen. Financial Knowledge (FK) dalam penelitian ini didefinsikan sebagai penguasaan seseorang atas berbagai hal tentang keuangan yang diturunkan menjadi 7 indikator yaitu: (1) pengetahuan tentang perencanaan keuangan, (2) pengetahuan tentang pengeluaran \& pemasukan, (3) pengetahuan uang \& aset, (4) pengetahuan tentang suku bunga, (5) pengetahuan tentang kredit, (6) pengetahuan dasar tentang asuransi, (7) pengetahuan dasar tentang investasi.

Financial Attitude (FA) merupakan sikap keuangan yang ada dalam pikiran, pendapat, dan penilaian tentang keuangan. Difinisi tersebut dijabarkan dalam 5 indikator yaitu: (1) obsession (pola pikir seseorang tentang uang dan persepsinya tentang masa depan untuk mengelola uang dengan baik, (2) power (menggunakan uang sebagai alat untuk mengendalikan orang lain), (3) effort (seseorang yang merasa pantas memiliki uang dari apa yang sudah dikerjakannya), -inadequacy (seseorang yang selalu merasa tidak cukup memiliki uang), (4) security (pandangan seseorang yang sangat kuno tentang uang seperti anggapan bahwa uang lebih baik hanya disimpan sendiri tanpa ditabung di bank atau untuk investasi). Financial Behavior (FB) didefinisikan sebagai perilaku seseorang dalam melakukan konsumsi, manajemen cash flow, saving and investment, dan serta manajemen credit yang kemudian di jabarkan menjadi 3 indikator yaitu (1) pengeluaran (2) pengaturan arus kas (3) perencanaan keuangan

Financial distress $(F D)$ atau kesulitan keuangan adalah keadaan dimana seseorang berada di bawah tekanan atau khawatir dan tidak puas dengan situasi keuangannya. Variabel ini diukur menggunakan kuesioner dengan indikator sebagai berikut: (1) no savings (tidak memiliki tabungan), (2) using credit for everyday bills (menggunakan kredit untuk tagihan harian), (3) making minimum payments (melakukan pembayaran minimum), (4) missing payments (tidak melakukan pembayaran), (5) borrowing from family \& friends (meminjam dari teman atau keluarga). Teknik analisis yang digunakan untuk melakukan pengolahan data dalam penelitian ini adalah analisis jalur. Analisis jalur dalam penelitian ini karena penelitian ini bertujuan untuk mengetahui pengaruh langsung dari FK dan FA terhadap FD maupun pengaruh tidak langsung FK dan FA terhadap FD melalui FB. Sebelum analisis jalur dilakukan dilakukan uji validitas dan reliabilitas terlebih dahulu agar hasil penelitian tidak bias, juga dilakukan uji normalitas data.

\section{Hasil}

Tabel 1.

Hasil Olah Data Persamaan I

\begin{tabular}{|c|c|c|c|}
\hline Variabel Independen & Beta & t-statistik & Sig \\
\hline$F K$ & 0,510 & 8,007 & 0,000 \\
\hline$F A$ & $-0,125$ & 7,548 & 0,044 \\
\hline $\mathrm{R}$ square & & & 0,258 \\
\hline F statistik & & & 28,513 \\
\hline Signifikansi & & & 0,000 \\
\hline
\end{tabular}

Sumber: data olahan

Berdasarkan tabel 1 dapat disimpulkan bahwa financial knowledge berpengaruh signifikan terhadap financial behavior dengan koefisien sebesar 0,510 dan tingkat signifikansi 0,000. Variabel financial attitude juga berpengaruh signifikan terhadap financial behavior dengan koefisien sebesar -0,125 dengan tingkat signifikansi 0,044. Model di atas menunjukkan bahwa variabel financial knowledge dan financial attitude memengaruhi perubahan financial behavior sebesar 25,8\% dengan tingkat signifikansi 0,000, sehingga model dianggap layak untuk pengujian hipotesis. Tahap berikutnya adalah pengujian financial knowledge, financial attitude, dan financial behavior terhadap financial distress. 
Cicilia Erna Susilawati dan Vania Dewi Sugiarto, Financial Behavior Sebagai Moderasi Pengaruh Financial Knowledge dan Financial Attitude Terhadap Financial Distress pada Generasi Milenial

Tabel 2.

Hasil Olah Data Persamaan II

\begin{tabular}{|c|c|c|c|}
\hline Variabel Independen & Beta & t-statistik & Sig \\
\hline$F B$ & $-0,323$ & $-0,3831$ & 0,000 \\
\hline$F K$ & 0,09 & 1,059 & 0,291 \\
\hline$F A$ & 0,446 & 6,612 & 0,000 \\
\hline R square & & & 0,296 \\
\hline F statistik & & & 22,84 \\
\hline Signifikansi & & & 0,000 \\
\hline
\end{tabular}

Sumber: data olahan

Berdasarkan Tabel 2 disimpulkan bahwa variabel financial behavior berpengaruh signifikan terhadap financial distress dengan koefisien sebesar 0,323 dan tingkat signifikansi sebesar 0,000, lebih kecil dari alpha 0,005. Financial knowledge tidak berpengaruh terhadap financial distress karena nilai signifikansi sebesar 0,291 lebih besar daripada alpha 0,05. Variabel financial attitude berpengaruh signifikan terhadap financial distress dengan koefisien sebesar 0,446 dan tingkat signifikansi 0,000 lebih kecil dari alpha 0,05. Model di atas menunjukkan bahwa variabel financial knowledge, financial attitude, dan financial behavior memengaruhi perubahan financial distress sebesar 29,6\% dengan nilai signifikansi 0,000 sehingga model dianggap layak untuk pengujian hipotesis.

Tabel 3.

Hasil Uji Hipotesis

\begin{tabular}{clrrl}
\hline No & \multicolumn{1}{c}{ Hipotesis } & Koefisien & Signifikansi & Kesimpulan \\
\hline 1. & FK-FB & 0,510 & 0,000 & H1 Diterima \\
2. & FA-FB & $-0,125$ & 0,044 & H2 Diterima \\
3. & FB-FD & $-0,323$ & 0,000 & H3 Diterima \\
4. & FK-FD & 0,09 & 0,291 & H4 Ditolak \\
5. & FA-FD & 0,0446 & 0,000 & H5 Diterima \\
6. & FK-FB-FD & $-0,16473$ & 0,000 & H6 Diterima \\
7. & FA-FB-FD & 0,0486 & 0,000 & H7 Diterima \\
\hline
\end{tabular}

Sumber: data olahan

Berdasarkan tabel diatas, dapat dikatakan bahwa Financial knowledge (FK) atau pengetahuan keuangan berpengaruh positif signifikan pada financial behavior atau perilaku keuangan. Nilai $\mathrm{t}$ yang positif menunjukkan bahwa semakin tinggi financial knowledge atau pengetahuan keuangan generasi milenial akan semakin baik pula perilaku keuangannya. Oleh karena itu, hipotesis yang menyatakan bahwa financial knowledge berpengaruh terhadap financial distress melalui financial behavior dapat diterima. Financial attitude (FA) atau sikap keuangan memiliki pengaruh negatif signifikan pada financial behavior atau perilaku keuangan. Nilai t yang negatif menunjukkan bahwa semakin buruk financial attitude atau sikap keuangan generasi milenial akan semakin baik perilaku keuangannya. Hasil koefisien negatif ini disebabkan karena beberapa pernyataan yang digunakan sebagai indikator penilaian dalam variabel financial attitude merupakan pernyataan negatif. Nilai signifikansi t yang didapat di bawah 0,05 atau berarti terdapat pengaruh yang signifikan FA terhadap FD. Oleh karena itu, hipotesis yang menyatakan bahwa financial attitude berpengaruh terhadap financial behavior dapat diterima.

Pada variabel Financial behavior $(F B)$ atau perilaku keuangan menunjukkan adanya pengaruh negatif signifikan pada financial distress $(F D)$. Nilai t yang negatif menunjukkan bahwa semakin baik financial behavior atau perilaku keuangan generasi milenial akan menghindarkan generasi milenial dari kesulitan keuangan sehingga hipotesis yang menyatakan bahwa financial behavior $(F B)$ berpengaruh terhadap financial distress (FD) dapat diterima. Financial knowledge tidak berpengaruh secara langsung terhadap financial distress, karena nilai signifikansinya lebih dari 0,05 , sehingga hipotesis yang menyatakan bahwa financial knowledge berpengauh langsung terhadap financial distress tidak terbukti. Financial attitude berpengaruh secara langsung terhadap financial distress karena nilai signifikansinya lebih kecil dari 0,05 , sehingga hipotesis yang menyatakan bahwa financial attitude berpenagruh langsung terhadap financial distress diterima. Financial knowledge berpengaruh terhadap financial distress melalui financial behavior karena berdasarkan hasil pengujian, financial knowledge tidak berpengaruh secara langsung terhadap financial distress. Akan tetapi, financial knowledge berpengaruh terhadap financial behavior dan financial behavior berpengaruh terhadap financial distress. Sehingga hipotesis yang menyatakan bahwa financial knowledge berpengaruh terhadap financial distress melalui financial behavior diterima. Financial attitude berpengaruh terhadap financial distress melalui financial behavior karena nilai koefisien pengaruh tidak langsung financial attitude terhadap financial distress melalui financial behavior lebih besar daripada koefisien financial attitude terhadap financial 
distress secara langsung. Jadi, hipotesis yang menyatakan bahwa financial attitude terhadap financial distress melalui financial behavior diterima.

Hasil penelitian ini menunjukkan bahwa financial knowledge berpengaruh positif signifikan terhadap financial behavior pada generasi milenial. Hal ini berarti bahwa pengetahuan keuangan generasi milenial yang baik menciptakan perilaku keuangan yang baik pula. Oleh karena itu, pengetahuan keuangan yang baik membuat generasi milenial mampu menggunakan uang dengan bijak atau menggunakan uang untuk memberikan manfaat bagi kehidupan mereka. Sebaliknya, pengetahuan keuangan generasi milenial yang rendah membuat generasi milenial tidak mampu mengelola keuangan dengan baik atau tidak dapat mengambil keputusan keuangan yang baik. Namun, penelitian ini juga membuktikan bahwa pengetahuan keuangan tidak berpengaruh secara langsung terhadap kesulitan keuangan. Pengetahuan keuangan yang dimiliki generasi milenial tidak menjamin generasi milenial terhindar dari kesulitan keuangan, jika pengetahuan keuangan yang dimiliki tidak diterapkan pada perilaku pengelolaan keuangan. Jadi, pengetahuan keuangan dapat mengurangi kemungkinan kesulitan keuangan apabila pengetahuan yang dimiliki diterapkan pada perilaku pengelolaan keuangan.

Penelitian ini juga menunjukkan bahwa financial attitude berpengaruh signifikan terhadap financial behavior pada generasi milenial. Semakin baik sikap keuangan generasi milenial, maka akan semakin baik pula perilaku keuangannya. Hal ini tentu tidak luput dari gaya hidup generasi milenial. Gaya hidup generasi milenial yang timbul dari sikap keuangan atau pemikiran tentang uang yang harus dihabiskan demi hal-hal konsumtif atau pengakuan sosial cenderung sulit untuk menabung. Kesulitan untuk menabung dan tidak membayar hutang inilah yang akan membawa seseorang ke financial distress atau kesulitan keuangan (Chinen, 2012). Selain itu financial behavior berpengaruh negatif signifikan terhadap financial distress pada generasi milenial. Oleh karena itu, semakin baik perilaku keuangan seseorang, maka semakin jauh pula orang tersebut terhindar dari financial distress. Salah satu tanda bahwa seseorang mengalami financial distress adalah tidak dapat membayar kredit atau hutang, sehingga cenderung meminjam kepada keluarga, teman, maupun pinjaman lain dengan bunga pinjaman yang tinggi. Sebaliknya, tanda seseorang tidak mengalami financial distress adalah mempunyai tabungan atau menyediakan dana darurat. Seseorang dengan financial behavior atau perilaku keuangan yang baik akan cenderung menyisihkan penghasilannya untuk ditabung sehingga terhindari dari financial distress. Sedangkan seseorang dengan keterampilan keuangan yang buruk akan cenderung memperburuk kesulitan keuangan. Hubungan kedua variabel ini berkaitan dengan variabel financial knowledge dan financial attitude yang berpengaruh terhadap financial behavior. Jadi, financial knowledge yang memengaruhi financial behavior secara positif signifikan, secara tidak langsung memengaruhi financial distress. Dengan kata lain, pengetahuan keuangan seseorang yang baik menghindarkan orang itu pula dari financial distress.

\section{Simpulan}

Financial knowledge tidak berpengaruh secara langsung terhadap financial distress. Hal ini menunjukkan bahwa pengetahuan keuangan yang dimiliki generasi milenial tidak menjamin generasi milenial terhindar dari kesulitan keuangan. Akan tetapi, financial knowledge memengaruhi financial distress melalui financial behavior. Artinya, jika pengetahuan keuangan yang dimiliki diterapkan pada perilaku pengelolaan keuangan, maka akan mengurangi kemungkinan terjadinya financial distress. Financial attitude berpengaruh langsung terhadap financial distress, dan berpengaruh melalui financial behavior. Hal ini menunjukkan bahwa sikap keuangan akan bisa memengaruhi kesulitan keuangan secara langsung, maupun melalui perilaku pengelolaan keuangan. Pengaruh financial attitude lebih besar terhadap financial distress melalui financial behavior. Jadi, financial behavior memiliki peran dalam mengurangi financial distress pada generasi milenial.

\section{Daftar Pustaka}

Adiputra, I. G. (2021), The Influence of Financial Literacy, Financial Attitude and Locus of Control on Financial Satisfaction: Evidence From the Community in Jakarta, 2021, pp. 636-654. doi: 10.18502/kss.v5i5.8848.

Anna, M. R., Consulting, R. and Stone, M. (2019), Financial Challenges for Millennials : How Do They Compare With Other Generations?, Benefit Quarterly, pp. 18-28.

Arifin, A. Z. (2018), Influence Factors toward Financial Satisfaction with Financial Behavior as Intervening Variable on Jakarta Area Workforce, XXI(1), pp. 90-103.

Chinen, K. (2012), Effects of Attitude and Background on Personal Financial Ability : A Student Survey in the United States, 29(1), p. 2012.

Eccles, D. . et al. (2014), Durham Research Online, ournal of Consumer A_airs, 44(August).

Halidi, R. (2021). Survei sebut generasi milenial buruk dalam kelola keuangan, kamu termasuk?. https://www.suara.com/lifestyle/2021/05/04/093522/survei-sebut-generasimilenial-buruk-dalam-kelolakeuangan-kamu-termasuk?page $=2$,

Hogarth, M. . J. and Hilgert, M. A. (2002). Financial Knowledge, Experience and Learning Preferences : Preliminary Results from a New Survey on Financial Literacy, Consumer Interest Annual, 48, pp. 1-7. 
Cicilia Erna Susilawati dan Vania Dewi Sugiarto, Financial Behavior Sebagai Moderasi Pengaruh Financial Knowledge dan Financial Attitude Terhadap Financial Distress pada Generasi Milenial

Huston, S. J. (2010), Measuring Financial Literacy, 44(2), pp. 296-316.

Lajuni, N., Bujang, I. and Yacob, Y. (2018), Religiosity, Financial Knowledge, and Financial Behavior Influence On Personal Financial Distress, 20(2), pp. 92-98. doi: 10.9744/jmk.20.2.92.

Lusardi, A. (2012), Numeracy, financial literacy, and financial decision-making.

Mien, N. T. N. and Thao, T. P. (2015), Factors Affecting Personal Financial Management Behaviors : Evidence from Vietnam, in Proceedings of the Second Asia-Pacific Conference on Global Business, Economics, Finance and Social Sciences (AP15Vietnam Conference) ISBN: 978-1-63415-833-6 Danang-Vietnam, 10-12 July, 2015 Paper ID: VL532.

Rajna, A. and Moshiri, H. (2011), Financial Management Attitude and Practice among the Medical Practitioners in Public and Private Medical Service in Malaysia Financial Management Attitude and Practice among the Medical Practitioners in Public and Private Medical Service in Malaysia, (August). doi: 10.5539/ijbm.v6n8p105.

Trial, O. C. et al. (2008), The Treatment of Disordered Money Behaviors : Results of an The Treatment of Disordered Money Behaviors : Results of an Open Clinical Trial, (August). doi: 10.1037/1541-1559.5.3.295. 